\title{
35 GHz Vivaldi Fed Antenna Design for Passive Millimeter Wave Imaging System in Ka Band
}

\author{
Mehmet Duman and Alp Oral Salman \\ Electronics and Communication Engineering, Faculty of Engineering, Kocaeli University, Kocaeli 41380, Turkey
}

\begin{abstract}
This antenna will be used for PMWIS (passive millimeter wave imaging system) which has 35 GHz operating frequency described as Ka Band. The antenna should work in that specific frequency because of having low attenuation in that region according to frequency behavior in misty conditions. Antenna also should have approximately $50 \mathrm{ohm}$ input impedance value so that perfect matching to the active circuits will occur. The input reflection coefficient, $\mathrm{S}_{11}$, has to be under $-20 \mathrm{~dB}$ and the gain of the antenna, has to be over 10 $\mathrm{dB}$ value for better efficiency. Microstrip Vivaldi Fed Antenna provides all of the conditions for imaging system, was designed by using Antenna Magus Computer Program and later it was designed in detail with Computer Simulation Technology Studio Suite Computer Program. The last format of the VFA has $-23.1 \mathrm{~dB}$ input reflection coefficient, $48.55 \mathrm{ohm}$ input impedance and $12.3 \mathrm{~dB}$ gain for $35 \mathrm{GHz}$ OF. It is ready to connect to the LNA and detector, which are active circuits of the PMWIS. At the end, the detector will be connected to the VA and computer. The receiver of PMWIS is composed to the VFA connected to the other equipment that is defined above will scan elevation and azimuth angles, as a result; the VA will transfer the signals to the computer. Computer will show the user the scanning area image. In this system, antenna is the most important section and particular attention was given to the antenna in this study.
\end{abstract}

Key words: Ka band, passive millimeter wave imaging, Vivaldi fed antenna.

\section{Nomenclature}

PMWIS: $\quad$ Passive Millimeter Wave Imaging System

CST: $\quad$ Computer Simulation Technology

GHz: Gigahertz

G: Gain

S: $\quad$ Scattering Parameter

VFA: $\quad$ Vivaldi Fed Antenna

PCB: $\quad$ Printed Circuit Board

dB: Decibel

LNA: $\quad$ Low Noise Amplifier

OF: $\quad$ Operating Frequency

VSWR: Voltage Standing Wave Ratio

RF: $\quad$ Radio Frequency

SMA: $\quad$ Subminiature Version A

PEC: $\quad$ Perfect Electric Conductance

VA: $\quad$ Video Amplifier

MATLAB: Matrix Laboratory Program

CF: $\quad$ Center Frequency

\section{Introduction}

Antennas are the most important parts of the

Corresponding author: Mehmet Duman, Ph.D. student, research assistant, research fields: microwave and millimeter wave engineering, electromagnetism, antennas and active circuits. electromagnetic circuits. The directivity, G, input reflection coefficient and coherence are figure of merits of the antennas. If the circuit is designed to the PCB, it will be the best choice to use microstrip antenna instead of horn antennas. Thanks to microstrip antenna, the converter from wave guide to PCB is not used, as a result; it will be less loss. In this work, VFA is designed to use with other circuits like LNA, detector and VA. The VFA has $12.3 \mathrm{~dB}$ G and $-23.1 \mathrm{~dB}$ input reflection coefficient $\left(\mathrm{S}_{11}\right)$ at $35 \mathrm{GHz} \mathrm{OF}$. The advantage of PMWIS is to provide viewing the image at foggy air conditions. The $35 \mathrm{GHz}, 96 \mathrm{GHz}$ and 220 $\mathrm{GHz}$ are some of the other important frequencies for PMWIS. The VFA's input impedance is $48.55 \Omega$, the closer to the $50 \Omega$, the better antenna design. In azimuth angle, the antenna scans from $-59.9^{\circ}$ to $59.9^{\circ}$ and in elevation angle, the antenna scans from $14.9^{\circ}$ to $104.9^{\circ}$. So that $899 \times 1,199$ pixel resolution image can occur on computer screen. The antenna will send the signals to the LNA and LNA transfers them to the VA. Therefore, the image will be on the computer screen in PMWIS 
application. The image on screen can be enhanced by other software. At the end, the view between scanning angles can be seen very well in foggy conditions. If the antenna works well, all of the system will work well too. In this paper, VFA for PMWIS is described in detail.

\section{Performance Parameters}

For most of the antennas, the input reflection coefficient $\left(\mathrm{S}_{11}\right)$ should be under $-20 \mathrm{~dB}$ and the input impedance should be close to the $50 \Omega$ RF impedance. Both of these conditions are achieved in this VFA. G and VSWR are the other parameters that particular attention should be given to for antenna design.

\subsection{Input Reflection Coefficient}

There are 3 frequency windows according to $S_{11}$ graph of the antenna. The CFs of these windows are $30.528 \mathrm{GHz}, 35.474 \mathrm{GHz}$ and $40.845 \mathrm{GHz}$ frequencies. For these frequencies, the input reflection coefficients have the minimum values. It can be said that, this design will work between $20 \mathrm{GHz}$ and $42 \mathrm{GHz}$ frequencies (Ka Band) because magnitudes are below $-20 \mathrm{~dB}$.

In this design, it is $-23.1 \mathrm{~dB}$ for $35 \mathrm{GHz} \mathrm{OF}$, see Fig. 1. All the simulations are done by two computer programs. In Fig. 2, the input reflection coefficient is obtained $-20.3 \mathrm{~dB}$ for $35 \mathrm{GHz}$ from Antenna Magus Computer Program. The frequency windows and CFs are very similar to the CST Studio Suite design.

\subsection{Input Impedance}

The LNA impedance is $50 \Omega$, the VFA will connect to the LNA circuit, therefore; the out part of the antenna should have $50 \Omega$ impedance too. In this design, it has $48.5 \Omega$ reference input impedance in Fig. 4. This value is acceptable for circuit analysis. Values for Fig. 3 are got from CST, mean real impedance is $47.28 \Omega$ and mean imaginary impedance is $-1.501 \Omega$ for Magus.

\subsection{Gain}

Gain, $G$, or $S_{21}$ is another specific performance parameter for antenna design. Most of the antennas should provide bigger than $10 \mathrm{~dB}$ G. The VFA's G for this design is greater than $10 \mathrm{~dB}$ after $24 \mathrm{GHz}$ frequency and it is $12.3 \mathrm{~dB}$ for $35 \mathrm{GHz} \mathrm{OF}$, see Fig. 5 .

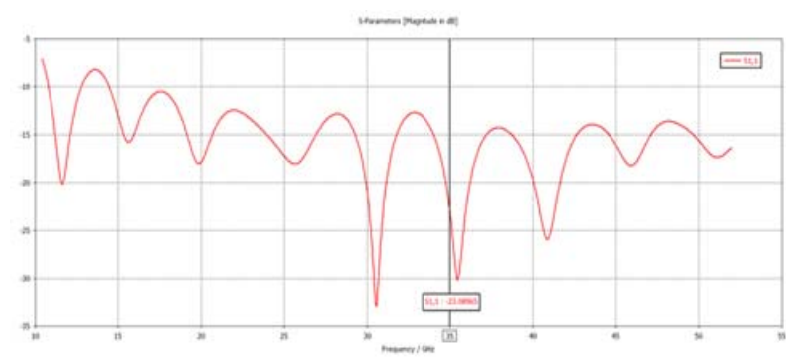

Fig. $1 S_{11}$ graph of the antenna from CST computer program.

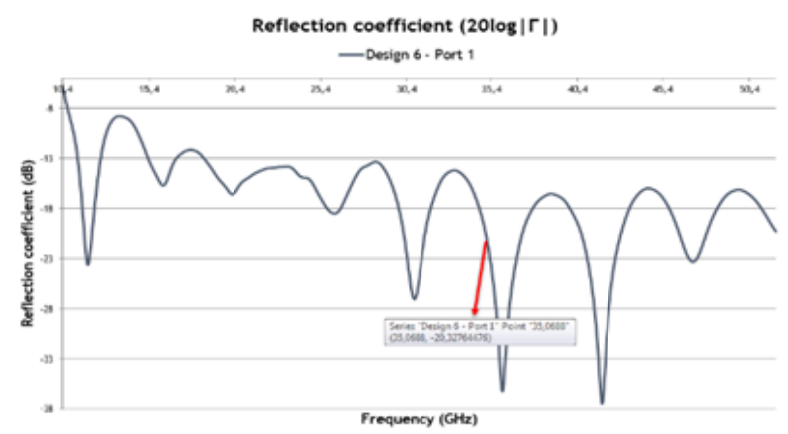

Fig. $2 S_{11}$ graph of the antenna from Magus computer program.

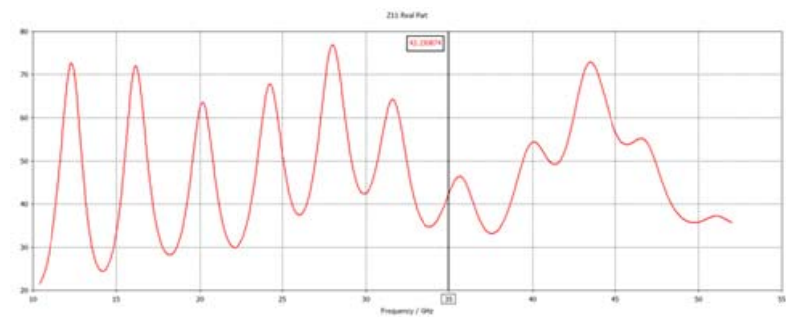

(a)

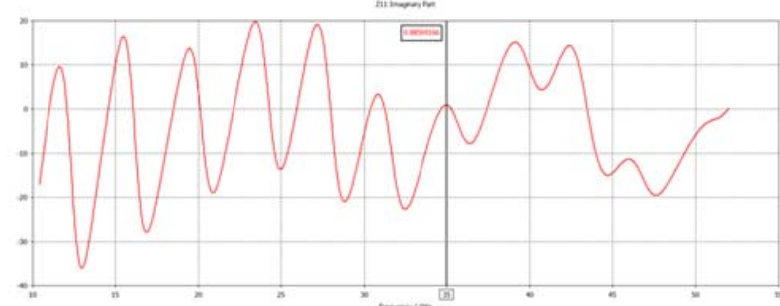

(b)

Fig. 3 (a) Real part of input impedance, (b) imaginer part of input impedance. 


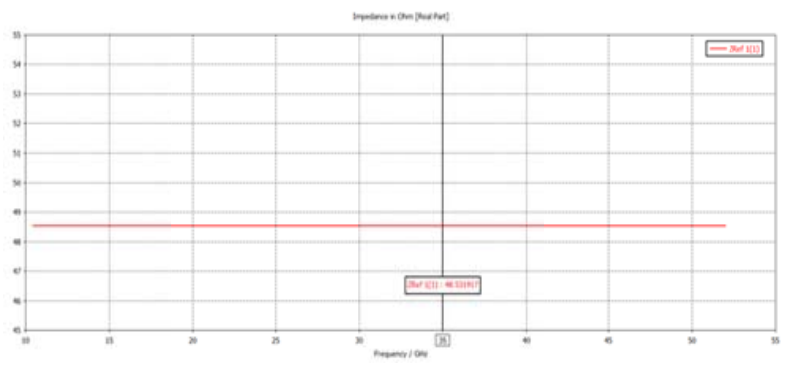

Fig. 4 Reference impedance.

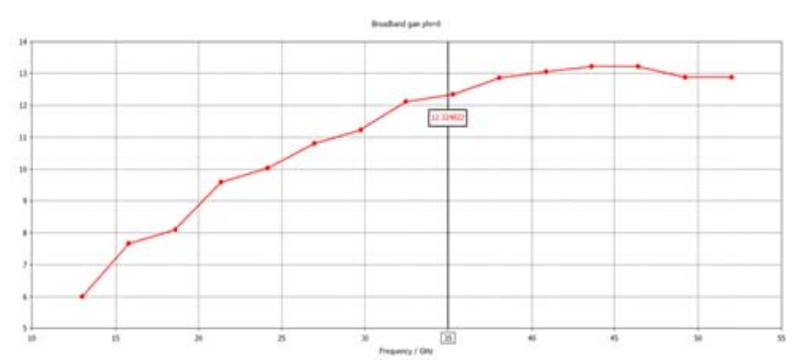

Fig. 5 Gain graph.

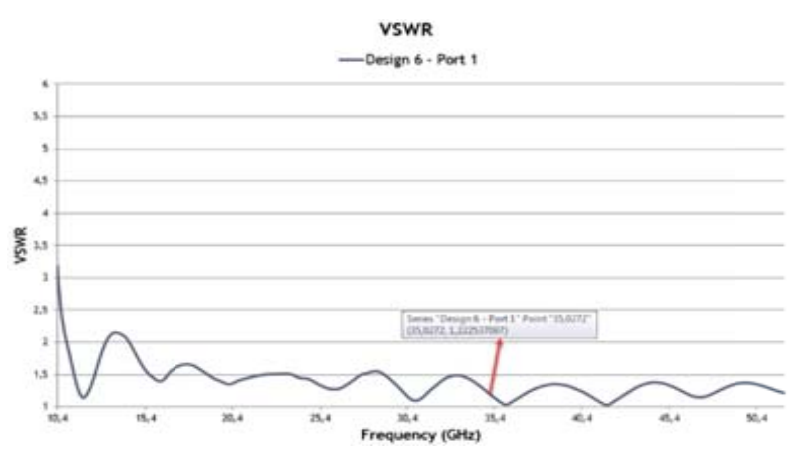

Fig. 6 VSWR graph.

\subsection{VSWR}

VSWR value should be close to 1 but not equal to 1 . In this design the VSWR value is 1.22 that can be seen in Fig. 6.

\section{Shape of Antenna}

Vivaldi antennas are very similar to the horn antennas, the only difference is that horn antennas have three dimensions, vivaldi antennas have two dimensions. Thanks to vivaldi antenna, the connector from horn to PCB is not used. Vivaldi antennas can be connected to the PCB easily. Because the OF is high, $2.92 \mathrm{~mm}$ connector will be used for experiments. SMA connectors are for up to $26.5 \mathrm{GHz}$. The antenna will be connected with $2.92 \mathrm{~mm}$ connector to the LNA and the

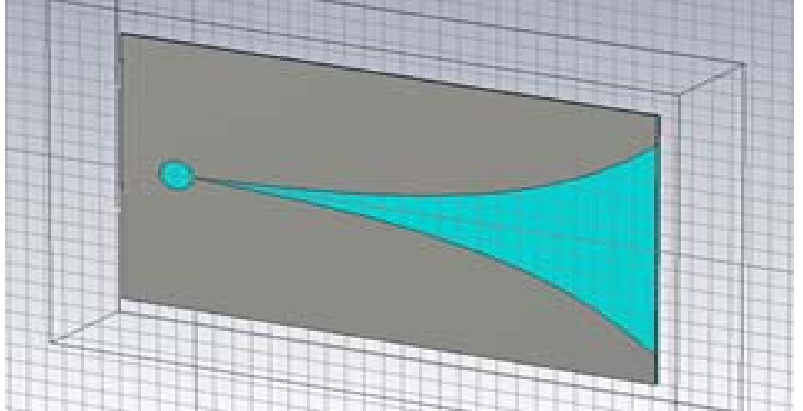

(a)

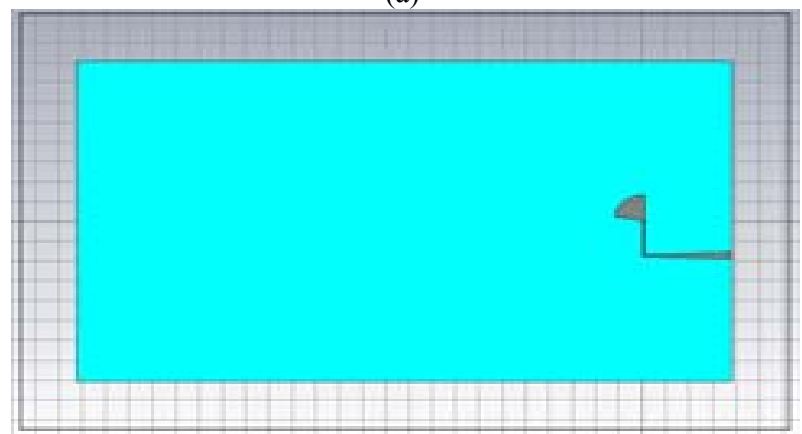

(b)

Fig. 7 (a) Perspective view of antenna; (b) Fed part of antenna.

LNA will connect to the detector. The substrate's epsilon value is 3.27 and $\mu$ is 1 for simulations. Loss tangent value is 0 . For the other parts of the antenna, PEC is used for simulations (Fig. 7a) and fed part of the antenna is also shown in Fig. 7b.

\section{Results and Simulations}

PMWIS applications work for some specific frequencies as $35 \mathrm{GHz}, 96 \mathrm{GHz}$ and $220 \mathrm{GHz}$. In this work, $35 \mathrm{GHz}$ frequency was used and VFA was designed for this OF. The performance parameters: input reflection coefficient, input impedance, $\mathrm{G}$ and VSWR values, were intensively studied. Lastly, shape of antenna was given in detail.

If the antenna connects to the other circuits like LNA, detector and VA, the image which is between azimuth and elevation scanning angles appears on the computer screen. After enhancements in the computer program such as MATLAB, the image will get well. In the end, the image will be seen in foggy air conditions.

\section{Acknowledgments}

The authors express their thanks to the Kocaeli 
University, Düzce University and TÜBİTAK (the Scientific and Technological Research Council of Turkey) for their supports and assistances.

\section{References}

[1] Balanis, C. A. 2013. Anten Teorisi Analiz ve Tasarım, (3rd ed.), Nobel Publishing, Wiley.

[2] Duman, M., and Salman, A. O. 2017. "Obtaining the Sky-Temperature Depending on Voltage Value by the Passive Millimeter Wave Imaging System." Presented at the Int. Advances in Applied Physics and Materials Science Congress and Exhibition, Muğla, Turkey, 22-26 April, 2017.

[3] Cripps, S. C. 1999. RF Power Amplifiers for Wireless Communications. Boston: Artech House.

[4] Pozar, D. M. 1998. Microwave Engineering. Hoboken: John Wiley \& Sons Inc.

[5] Cheng, D. K. Field and Wave Electromagnetics, (2nd ed.), Syracuse University, Addison-Wesley Publishing
Company.

[6] Antenna Magus Computer Program Information Browser. 2014.

[7] Yarman, B. S. 2010. "Design of Ultra-wideband Power Transfer Networks." College of Engineering, Department of Electrical Electronics Engineering, Istanbul University, Istanbul.

[8] Duman, M. 2016. "Pasif milimetre dalga görüntüleme sistemi için Ka bandı $(8 \mathrm{~mm})$ radyometrik alıcının geliştirilmesi ve uygulamaları.” 2. Follow-up Report, Kocaeli University, Kocaeli, Turkey.

[9] Duman, M., and Salman, A. O. 2017. "Designing a Vivaldi Fed Antenna for Passive Millimeter Wave Imaging System in Ka Band." Presented at the Int. Conf. on Engineering Technology and Innovation, Sarajevo, Bosnia and Herzegovina, 22-26 March, 2017.

[10] Duman, M. 2013. "UHF RF Power Amplifier Design and Implementation for Small Satellites." M.Sc. Thesis, İstanbul Technical University, İstanbul, Turkey. 